OPEN ACCESS

Edited by:

Lei Xi,

Virginia Commonwealth University,

United States

Reviewed by:

Chin Moi Chow,

University of Sydney, Australia Federica del Monte, Medical University of South Carolina, United States

${ }^{*}$ Correspondence: Maurizio Sessa

maurizio.sessa@sund.ku.dk maurizio.sessa@unicampania.it

tThese authors have contributed equally to this work as co-first authors

¥These authors have contributed equally to this work as co-lead authors

Specialty section: This article was submitted to Translational Pharmacology, a section of the journal Frontiers in Pharmacology

Received: 02 July 2018 Accepted: 05 October 2018 Published: 25 October 2018

Citation:

Sessa M, Mascolo A, Scavone C, Perone I, Di Giorgio A, Tari M, Fucile A, De Angelis A,

Rasmussen DB, Jensen MT, Kragholm K, Rossi F, Capuano A and Sportiello L (2018) Comparison of Long-Term Clinical Implications of Beta-Blockade in Patients With Obstructive Airway Diseases Exposed to Beta-Blockers With Different B1-Adrenoreceptor Selectivity: An Italian Population-Based Cohort

Study. Front. Pharmacol. 9:1212. doi: 10.3389/fphar.2018.01212

\section{Comparison of Long-Term Clinical Implications of Beta-Blockade in Patients With Obstructive Airway Diseases Exposed to Beta-Blockers With Different $\beta 1$-Adrenoreceptor Selectivity: An Italian Population-Based Cohort Study}

\author{
Maurizio Sessa ${ }^{1,2 * t}$, Annamaria Mascolo ${ }^{2 \dagger}$, Cristina Scavone ${ }^{2}$, Ilaria Perone ${ }^{2}$, \\ Annalisa Di Giorgio ${ }^{3}$, Michele Tari ${ }^{3}$, Annamaria Fucile ${ }^{3}$, Antonella De Angelis's, \\ Daniel Bech Rasmussen ${ }^{4,5,6}$, Magnus Thorsten Jensen ${ }^{5}$, Kristian Kragholm ${ }^{7,8}$, \\ Francesco Rossi ${ }^{2}$, Annalisa Capuano ${ }^{2 \ddagger}$ and Liberata Sportiello ${ }^{2 f}$ \\ 'Department of Drug Design and Pharmacology, University of Copenhagen, Copenhagen, Denmark, ${ }^{2}$ Department \\ of Experimental Medicine, University of Campania "L. Vanvitelli", Naples, Italy, ${ }^{3}$ Caserta Local Health Service, Caserta, Italy, \\ ${ }^{4}$ Respiratory Research Unit Zealand, Department of Respiratory Medicine, Naestved Hospital, Naestved, Denmark, \\ ${ }^{5}$ Department of Cardiology, Herlev and Gentofte University Hospital, Hellerup, Denmark, ${ }^{6}$ Department of Regional Health \\ Research, University of Southern Denmark, Odense, Denmark, ${ }^{7}$ Department of Cardiology, North Denmark Regional \\ Hospital, Hjørring, Denmark, ${ }^{8}$ Department of Cardiology, Aalborg University Hospital, Aalborg, Denmark
}

Rationale: Long-term clinical implications of beta-blockade in obstructive airway diseases remains controversial. We investigated if within the first 5 years of treatment patients with heart failure and obstructive airway diseases using non $\beta 1$-adrenoreceptor selective beta-blockers have an increased risk of being hospitalized for all-causes, heart failure, and chronic obstructive pulmonary disease (COPD) when compared to patient using selective beta-blockers.

Methods: Carvedilol users were propensity matched 1:1 for co-treatments, age, gender, and year of inclusion in the cohort with metoprolol/bisoprolol/nebivolol users. Cox proportional hazard regression model was used to compare all causes, COPD, and heart failure hospitalization or the beta-blocker discontinuation between cohorts. For statistically significant associations, we computed the rate difference and the attributable risk.

Results: Overall, 11,844 patients out of the 51,214 (23.1\%) were exposed to carvedilol and $39,370(76.9 \%)$ to metoprolol/bisoprolol/nebivolol. Carvedilol users had a higher hazard for heart failure hospitalization (HR 1.29; 95\% Confidence Interval [Cl] 1.181.40) with $106(95 \% \mathrm{Cl} 76-134$; $p$-value $<0.001)$ additional cases of heart failure hospitalization per 10000 person-years if compared to metoprolol/bisoprolol/nebivolol users. In all, 26.8\% $(95 \% \mathrm{Cl} 22.5-30.9 \%$; $p$-value $<0.001)$ of heart failure hospitalizations in the study population could be attributed to being exposed 
to carvedilol. Carvedilol users had a higher hazard $(\mathrm{HR} 1.06 ; 95 \% \mathrm{Cl} 1.02-$ 1.10) of discontinuing the pharmacological treatment with $131(95 \% \mathrm{Cl} 62-201$; $p$-value < 0.001) additional cases of beta-blocker discontinuation per 10000 person-years metoprolol/bisoprolol/nebivolol users. In all, 6.5\% $(95 \% \mathrm{Cl} 3.9-9.0 \%$; $p$-value < 0.001) of beta-blocker discontinuation could be attributed to being exposed to carvedilol.

Conclusion: On long-term follow-up period, carvedilol was associated with a higher risk of heart failure hospitalization and discontinuation if compared to metoprolol/bisoprolol/nebivolol users among patients with heart failure and obstructive airway diseases.

Keywords: clinical epidemiology, obstructive respiratory diseases, humans, pharmacoepidemiology, pharmacology, beta-blockers, heart failure

\section{INTRODUCTION}

Beta-blockers are able to reduce mortality in patients with concurrent heart failure and respiratory diseases and, therefore, the co-existence of both diseases should not discourage the clinicians from using these drugs (Rutten et al., 2010; Short et al., 2011; Du et al., 2014; Lim et al., 2017). While betablockade is clinically useful for heart failure, it could induce bronchoconstriction and worsen lung function in patients with asthma or chronic obstructive pulmonary disease (COPD) (Grieco and Pierson, 2017). Among beta-blockers approved for heart failure, those less selective for $\beta 1$-adrenoreceptor, such as carvedilol, were associated with a higher risk of obstructive airway diseases exacerbations (van der Woude et al., 2005; Hawkins et al., 2009; Short et al., 2011, 2014). In fact, European Society of Cardiology (ESC) and Global Initiative for Chronic Obstructive Lung Disease (GOLD) clinical guidelines recommended more selective $\beta 1$-adrenoreceptor antagonist in patients with concurrent heart failure and respiratory diseases (i.e., COPD and asthma) (Dickstein et al., 2008, 2010; McMurray et al., 2012; Ponikowski et al., 2016). However, the majority of studies comparing $\beta 1$-selective and non-selective beta-blockers in patients with heart failure and concurrent respiratory diseases focused on short-term follow-up period post beta-blockers initiation and only a few studies provided outcomes of public health interest (Salpeter et al., 2002; Hawkins et al., 2009; Jabbour et al., 2010; Rutten et al., 2010; Dungen et al., 2011; Lainscak et al., 2011; Etminan et al., 2012; Kubota et al., 2015; Ponikowski et al., 2016; Sessa et al., 2017a). Studies investigating clinical implications of beta-blockade on a long-term follow-up period are necessary, considering that the clinical implications observable during the start of beta-blocker initiation/up-titration do not necessarily reflect those occurring in the later phases of treatment (Baker and Wilcox, 2017). The first period of treatment with beta-blockers represents the most critical for bronchoconstriction because patients are up titrated to receive the optimal dosage of beta-blocker (Grieco and Pierson, 2017). In the later phases, when patients are symptomatically stable, there is a tendency to preserve a stable posological schema (Dickstein et al., 2008, 2010; McMurray et al., 2012; Ponikowski et al., 2016).
Moreover, patients with asthma or COPD could have been exposed for a long period to $\beta 2$-adrenoreceptor agonist, a phenomenon promoting the development of $\beta 2$-adrenoreceptor desensitization in the respiratory system (Hausdorff et al., 1990; Lohse et al., 1996; Chong et al., 2003). Consequently, patients could be less sensitive to acute beta-blockade effects in the respiratory system due to both desensitization mechanisms of $\beta 2$-adrenoreceptor and to the competitive binding of $\beta 2$ adrenoreceptor agonist that are typically co-administrated in patients having both diseases. However, on long-term, the prolonged $\beta 2$-adrenoreceptor antagonism performed by betablockers less selective for $\beta 1$-adrenoreceptor receptors can alter pulmonary compliance leading to dynamic hyperinflation even in presence of $\beta 2$-adrenoreceptor agonists (Jabbal and Lipworth, 2018). Dynamic hyperinflation, in turn, apart from negative respiratory outcomes, can promote impaired ventricular filling and low cardiac output along with a reduction of intrathoracic blood volume and pulmonary vein dimensions, all phenomenon that can promote decompensation of heart failure (Jorgensen et al., 2007; Watz et al., 2010; Barr et al., 2012; Stone et al., 2016; Watz, 2016). In this clinical scenario, $\beta 1$-adrenoreceptor selectivity of beta-blockers may still play a key role for the recrudescence of both heart failure and obstructive airway diseases symptoms. To provide further insight on this aspect we investigated if patients with heart failure and concurrent COPD or asthma with long-term exposure to low $\beta 1$ adrenoreceptor selectivity beta-blockers have an increased risk of being hospitalized for all-causes, heart failure, and obstructive airway diseases compared to non-selective beta-blockers.

\section{MATERIALS AND METHODS}

\section{Data Sources}

Caserta Local Health Unit administrative databases were used as data sources. For reimbursement purposes, these databases contain information on age, gender, date of birth, and death, drugs redeemed/supplied and hospitalization occurred for more than 1,000,000 citizens living in the catchment area of Caserta (Campania Region, Italy). For each redeemed prescription, we 
retrieved information on the active ingredient, the Anatomical Therapeutic Chemical (ATC) classification code, the quantity, and the dispensing date. According to the Italian law for confidentiality data, in each administrative database, critical information for privacy are encrypted and a unique anonymized identifier guarantee the linkage among these databases.

\section{Study Population}

The study population was composed of patients that redeemed carvedilol, metoprolol, bisoprolol or nebivolol prescriptions along with drugs for obstructive airway diseases (ATC R03) from December 31, 2010 to September 30, 2017. Given the different cardioselectivity of aforementioned $\beta$ blockers, which are all indicated for heart failure, patients were divided into two cohorts, those exposed to carvedilol (lower $\beta 1$-adrenoreceptor selectivity) and those exposed to metoprolol/bisoprolol/nebivolol (higher $\beta 1$-adrenoreceptor selectivity). We believe that by including patients co-exposed to reimbursed drugs for obstructive airway diseases (ATC R03) it is possible to identify both patients with asthma and COPD, however, mainly patients with COPD. In fact, Caserta Local Health Unit pharmaceutical administrative databases contain redeemed prescriptions for drugs that are reimbursed by the Italian Healthcare system. Those having ATC code R03 include aclidinium, beclomethasone, beclomethasone/formoterol, budesonide, budesonide/formoterol, fluticasone, formoterol, glycopyrronium, indacaterol, indacaterol/glycopyrronium, ipratropium bromide, nedocromil, salbutamol, salmeterol, salmeterol/fluticasone, theophylline, and tiotropium (Italian Medicine Agency, 2017). While some of these drugs are indicated for both asthma and COPD, the use of beta-blockers in asthma is contraindicated in both summaries of product characteristics and current clinical guidelines (Bousquet et al., 2007; Dickstein et al., 2008, 2010; McMurray et al., 2012; Ponikowski et al., 2016).

\section{Follow-Up Period}

The first date of co-exposure to beta-blocker and R03 drugs was used as the index date for each patient. Patients were followed through Caserta Local Health Unit administrative databases from index date to outcome or censoring at death or at the end of follow-up on September 30, 2017.

\section{Outcomes}

The first, second and third primary outcomes were the hazard ratio (HR) of being hospitalized for all causes, COPD and heart failure within 60 months from the index date for carvedilol users vs. metoprolol/bisoprolol/nebivolol users. The HR of discontinue the beta-blocker within 60 months from the index date for carvedilol users vs. metoprolol/bisoprolol/nebivolol users was also investigated.

\section{Study Covariates}

Age, gender, and co-treatments were obtained at index date.

\section{Statistical Analyses}

At index date, baseline characteristics of men and women were compared using the $t$-tests for continuous variables and $\chi^{2}$ test for categorical variables. To estimate the period of treatment with carvedilol or metoprolol/bisoprolol/nebivolol, the ongoing exposure was calculated for each individual by dividing the number of posological units dispensed by the estimated average dosage for the heart failure indication as described elsewhere (Andersson et al., 2012). Prior to data analyses, at index date, we matched patients exposed to carvedilol with those exposed to metoprolol/bisoprolol/nebivolol with a 1:1 match for our study covariates using the neighborhood matching algorithm (Austin, 2014). Histograms of propensity score were plotted prior and after matching to examine the effectiveness of the matching algorithm in balancing the covariates between the two cohorts. For the matched cohorts, cumulative incidence curves were generated to compare cumulative incidence for the study outcomes. Gray's test was used to evaluate the hypotheses that cause-specific cumulative functions were equal. Cox proportional hazard regression model with only outcome and exposure was used to compare the hazard of all causes, COPD, and heart failure hospitalization or beta-blocker discontinuation between the two cohorts. For statistically significant associations, we computed the rate difference and the attributable risk percentage for the outcome under investigation for carvedilol users as opposed to metoprolol/bisoprolol/nebivolol users as described elsewhere (Davis et al., 2003; Xu et al., 2010). All analyses were based on intention-to-treat approach and used a statistically significant level of $p<0.05$ (2-sided).

\section{Compliance With Ethical Standards}

In Italy, retrospective register-based studies do not require informed consent or ethical approval (Agenzia Italiana del Farmaco, 2008).

\section{RESULTS}

In Caserta Local Health Unit (Italy) administrative databases, we identified 51,214 patients exposed to $\beta$-blockers for heart failure (carvedilol, metoprolol, bisoprolol and nebivolol) concurrently with obstructive airway diseases drugs (ATC R03). Out of the 51,214 patients, $11,844(23.1 \%)$ were exposed to carvedilol and $39,370(76.9 \%)$ to metoprolol/bisoprolol/nebivolol. By matching 1:1 carvedilol users with metoprolol/bisoprolol/nebivolol users, we obtained the study population of 23,688 patients (Table 1 ). The matching was successful and is presented in Table $\mathbf{1}$ and Supplementary Figure 1. Patients exposed to carvedilol were followed for 29,828 person-years, while those exposed to metoprolol/bisoprolol/nebivolol for 31,270 person-years in Caserta Local Health Unit administrative databases.

\section{Comparison of All-Cause, Chronic Obstructive Pulmonary Disease, and Heart Failure Hospitalization Between Carvedilol and Metoprolol/Nebivolol/Bisoprolol Users}

All-causes, COPD and heart failure cumulative incidence curves for carvedilol and metoprolol/bisoprolol/nebivolol 
TABLE 1 | Demographic characteristics and concurrent pharmacological treatments of patients exposed to carvedilol or metoprolol/bisoprolol/nebivolol in the period 2010-2017 among those assisted by general practitioners of Caserta Local Health Unit (Italy).

\begin{tabular}{|c|c|c|c|c|c|}
\hline Variable & Level & $\begin{array}{l}\text { Carvedilol } \\
(n=11,844)\end{array}$ & $\begin{array}{c}\text { Metoprolol/ } \\
\text { bisoprolol/nebivolol } \\
(n=11,844)\end{array}$ & $\begin{array}{c}\text { Total } \\
(n=23,688)\end{array}$ & $p$-value \\
\hline Age & mean (SD) & $74.4(12.6)$ & $74.2(13.4)$ & $74.3(13.0)$ & 0.188 \\
\hline Gender & Male & $5858(49.5)$ & $5801(49.0)$ & 11659 (49.2) & 0.466 \\
\hline \multirow[t]{7}{*}{ Year of inclusion } & 2011 & 3131 (26.4) & $2968(25.1)$ & $6099(25.7)$ & \\
\hline & 2012 & $2916(24.6)$ & 2959 (25.0) & $5875(24.8)$ & \\
\hline & 2013 & $2067(17.5)$ & $2044(17.3)$ & $4111(17.4)$ & \\
\hline & 2014 & $1259(10.6)$ & $1350(11.4)$ & $2609(11.0)$ & \\
\hline & 2015 & $1146(9.7)$ & 1289 (10.9) & 2435 (10.3) & \\
\hline & 2016 & $906(7.6)$ & $864(7.3)$ & $1770(7.5)$ & \\
\hline & 2017 & 419 (3.5) & $370(3.1)$ & 789 (3.3) & 0.126 \\
\hline $\begin{array}{l}\text { Angiotensin-converting enzyme } \\
\text { inhibitors }\end{array}$ & $\mathrm{N}(\%)$ & $4211(35.6)$ & $1321(36.5)$ & $8532(36.0)$ & 0.264 \\
\hline $\begin{array}{l}\text { Hydroxymethylglutaryl-CoA } \\
\text { reductase inhibitors }\end{array}$ & $\mathrm{N}(\%)$ & $894(7.5)$ & $878(7.4)$ & $1772(7.5)$ & 0.711 \\
\hline $\begin{array}{l}\text { Angiotensin II Receptor } \\
\text { Blockers }\end{array}$ & $\mathrm{N}(\%)$ & $2726(23.0)$ & $2658(22.4)$ & $5384(22.7)$ & 0.139 \\
\hline Calcium channel blockers & $\mathrm{N}(\%)$ & 3075 (26.0) & $3014(25.4)$ & $6089(25.7)$ & 0.372 \\
\hline Vitamin $\mathrm{K}$ antagonist & $\mathrm{N}(\%)$ & $941(7.9)$ & $958(8.1)$ & $1899(8.0)$ & 0.701 \\
\hline Low-dose acetylsalicylic acid & $\mathrm{N}(\%)$ & $4498(38.0)$ & $4460(37.7)$ & $8958(37.8)$ & 0.620 \\
\hline Loop diuretics & $\mathrm{N}(\%)$ & $4191(35.4)$ & 4268 (36.0) & $8459(35.7)$ & 0.302 \\
\hline Potassium-sparing diuretics & $\mathrm{N}(\%)$ & $1827(15.4)$ & $1852(15.6)$ & $3679(15.5)$ & 0.666 \\
\hline $\begin{array}{l}\text { Sodium-Channel Blockers } \\
\text { (Class I Antiarrhythmics)* }^{*}\end{array}$ & $\mathrm{~N}(\%)$ & $252(2.1)$ & $260(2.2)$ & $512(2.2)$ & 0.754 \\
\hline $\begin{array}{l}\text { Potassium-Channel Blockers } \\
\text { (Class III Antiarrhythmics)* }^{*}\end{array}$ & $\mathrm{~N}(\%)$ & $580(4.9)$ & $595(5.0)$ & $1175(5.0)$ & 0.675 \\
\hline Organic nitrates & $\mathrm{N}(\%)$ & $1722(14.5)$ & $1785(15.1)$ & $3507(14.8)$ & 0.256 \\
\hline Anticholinergic long-acting & $\mathrm{N}(\%)$ & $2153(18.2)$ & $2126(18.0)$ & $4279(18.1)$ & 0.440 \\
\hline Anticholinergic short-acting & $\mathrm{N}(\%)$ & $566(4.8)$ & $582(4.9)$ & $1148(4.8)$ & 0.649 \\
\hline Beta 2 agonist + anticholinergic & $\mathrm{N}(\%)$ & & & & \\
\hline $\begin{array}{l}\text { Beta } 2 \text { agonist long-acting - } \\
\text { inhalers }\end{array}$ & $\mathrm{N}(\%)$ & $584(4.9)$ & $611(5.2)$ & $1195(5.0)$ & 0.440 \\
\hline $\begin{array}{l}\text { Beta } 2 \text { agonist short-acting - } \\
\text { inhalers }\end{array}$ & $\mathrm{N}(\%)$ & $876(7.4)$ & $950(8.0)$ & $1826(7.7)$ & 0.075 \\
\hline Glucorticoid + beta 2 agonist & $\mathrm{N}(\%)$ & 7995 (67.5) & $7950(67.1)$ & $15945(67.3)$ & 0.542 \\
\hline Glucorticoids - inhalers & $\mathrm{N}(\%)$ & $6715(56.7)$ & $6651(56.2)$ & $13366(56.4)$ & 0.409 \\
\hline Mast-cell stabilizer & $\mathrm{N}(\%)$ & $1745(14.7)$ & $1819(15.4)$ & $3564(15.0)$ & 0.184 \\
\hline Leukotriene receptor antagonist & $\mathrm{N}(\%)$ & $193(1.6)$ & $196(1.7)$ & $389(1.6)$ & 0.918 \\
\hline Phosphodiesterase inhibitors & $\mathrm{N}(\%)$ & $1557(13.1)$ & 1606 (13.6) & 3163 (13.4) & 0.359 \\
\hline
\end{tabular}

*According to Vaughan-Williams classification of antiarrhythmic drugs (Vaughan Williams, 1984).

users are provided in Figures 1-3, respectively. Within 60 months from the index date, no statistically significant differences were found for the hazard of being hospitalized for all causes (HR 1.00; 95\% confidence interval (CI) 0.96-1.04) or COPD (HR 1.04; 95\%CI 0.91-1.19) between carvedilol and metoprolol/bisoprolol/nebivolol users. For heart failure hospitalization, carvedilol users had a higher hazard compared with metoprolol, bisoprolol, and nebivolol users (HR 1.29; 95\%CI 1.18-1.40). Additionally, within the same follow-up period, carvedilol users had a higher hazard (HR 1.06; 95\%CI 1.02-1.10) of discontinuing the beta-blocker if compared to patients exposed to metoprolol/bisoprolol/nebivolol (Figure 4).

\section{Rate Difference and Attributable Risk Percentage of Heart Failure Hospitalization and Treatment Discontinuation for Carvedilol Users as Opposed to Metoprolol/Bisoprolol/Nebivolol}

By computing the rate difference between the two cohorts, it was found that patients exposed to carvedilol had 106 (95\%CI 76-134; $p$-value $<0.001)$ additional cases of heart failure hospitalization per 10,000 person-years when compared to patients exposed to metoprolol/bisoprolol/nebivolol. In all, 26.8\% (95\%CI 22.5-30.9\%; $p$-value $<0.001)$ of heart 


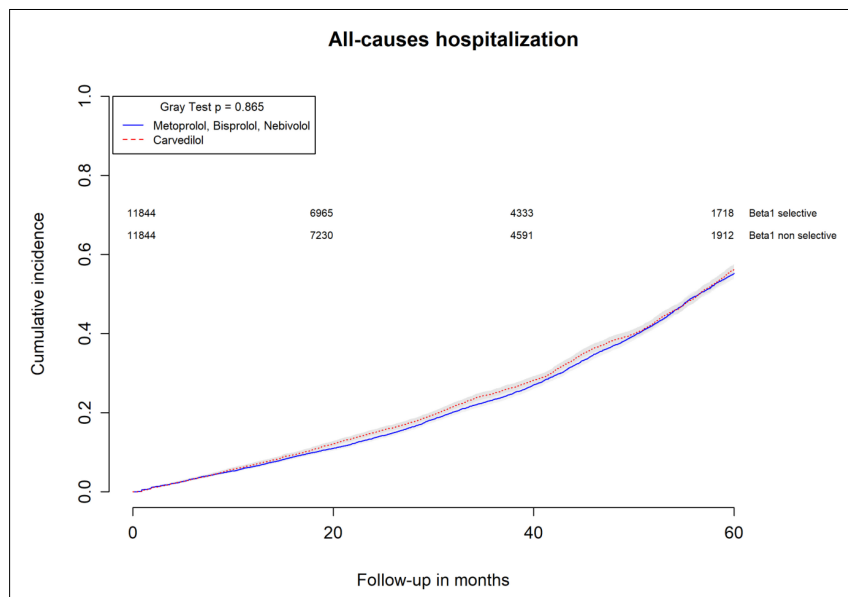

FIGURE 1 | Cumulative incidence curves for all-cause hospitalization in carvedilol users vs. metoprolol, bisoprolol, and nebivolol users.

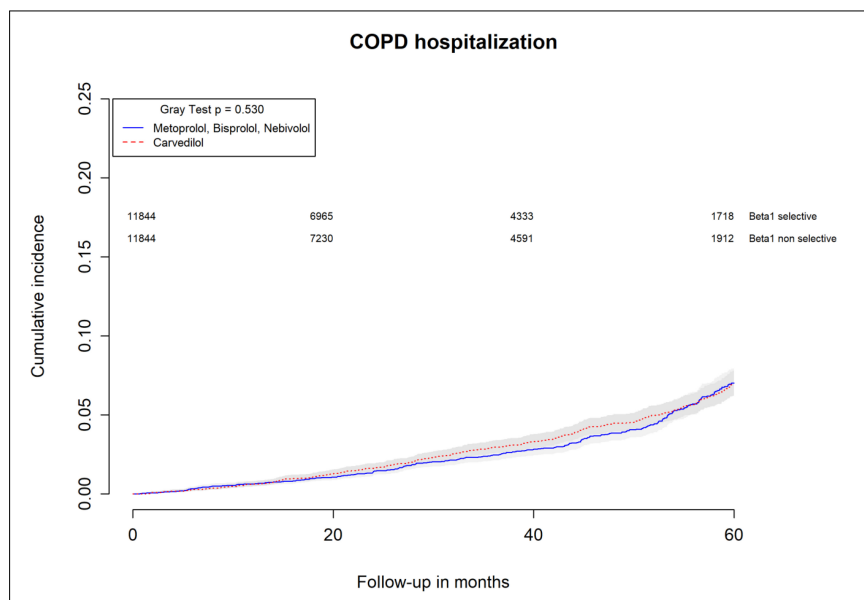

FIGURE 2 | Cumulative incidence curves for COPD hospitalization in carvedilol users vs. metoprolol, bisoprolol, and nebivolol users.

failure hospitalizations were attributed to carvedilol exposure. Patients exposed to carvedilol had 131 (95\%CI 62-201; $p$-value $<0.001)$ additional cases of beta-blocker discontinuation per 10,000 person-years when compared to patients exposed to metoprolol/bisoprolol/nebivolol. In all, 6.5\% (95\%CI 3.9$9.0 \%$; $p$-value $<0.001$ ) of beta-blocker discontinuation could be attributed to being exposed to carvedilol.

\section{DISCUSSION}

This study provided evidence on the impact of long-term beta-blocker administration for all causes, COPD, heart failure hospitalization or beta-blocker discontinuation within the first 60 months of treatment for carvedilol and metoprolol/bisoprolol/nebivolol users co-treated with drugs for COPD or asthma. On a long-term follow-up period, carvedilol use was associated with an increased hazard of heart failure hospitalization while no statistically significant differences were

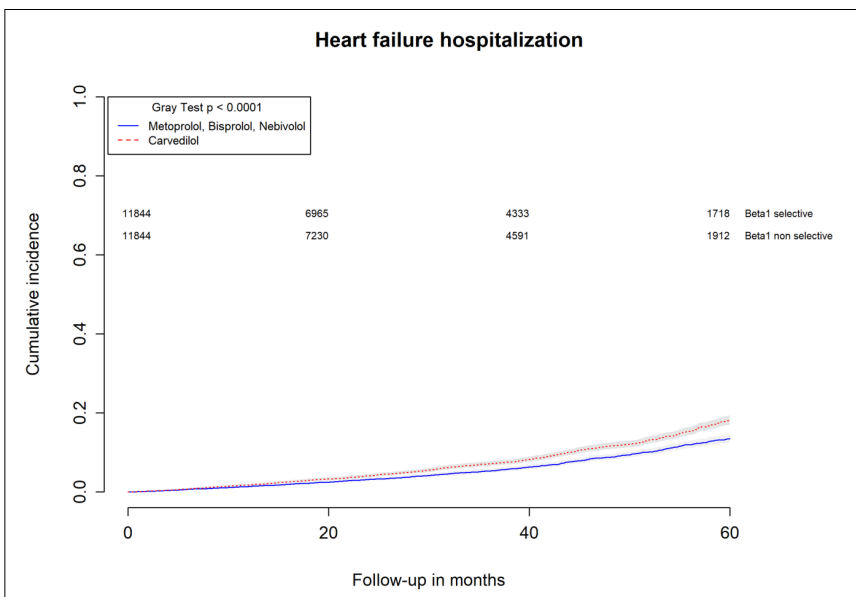

FIGURE 3 | Cumulative incidence curves for heart failure hospitalization in carvedilol users vs. metoprolol, bisoprolol, and nebivolol users.

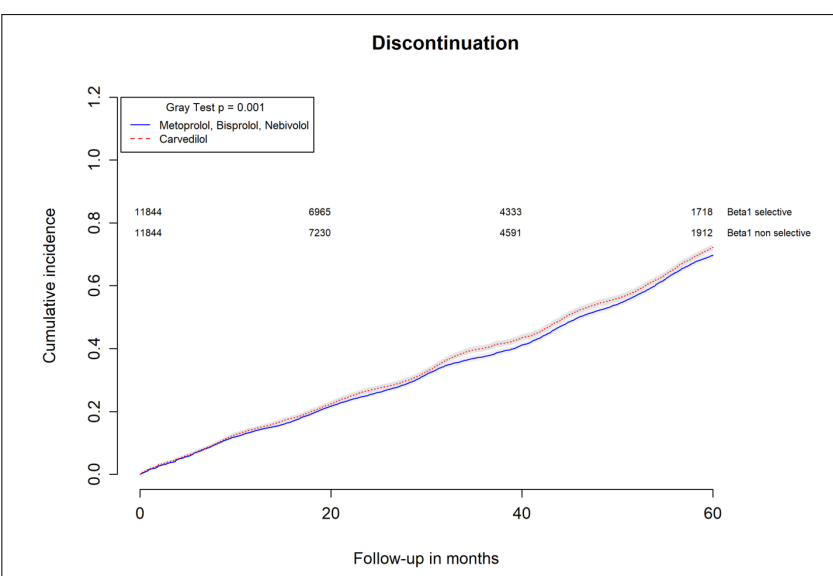

FIGURE 4 | Cumulative incidence curves for beta-blocker discontinuation in carvedilol users vs. metoprolol, bisoprolol, and nebivolol users.

observed for all-cause and COPD hospitalizations. Additionally, carvedilol users were found to discontinue beta-blocker treatment more than metoprolol/bisoprolol/nebivolol users. Our results are in line with previous studies investigating this topic (Salpeter et al., 2002; Jabbour et al., 2010; Dungen et al., 2011; Lainscak et al., 2011; Etminan et al., 2012; Loth et al., 2014; Morales et al., 2014, 2017; Kubota et al., 2015; Baker and Wilcox, 2017; Sessa et al., 2017a) despite aforementioned studies evaluated different clinical outcomes and used different follow-up periods (Salpeter et al., 2002; Hawkins et al., 2009; Jabbour et al., 2010; Dungen et al., 2011; Lainscak et al., 2011; Etminan et al., 2012; Kubota et al., 2015; Ponikowski et al., 2016; Sessa et al., 2017a). Despite being unable to provide any causal explanation for our results, we believe that the clinical management of these patients may have played a key role in our findings. In fact, while in the start of the beta-blocker treatment patients tends to be highly monitored because of the higher risk of bronchoconstriction, in the later phases patients tend to be less strictly monitored (Gottlieb et al., 2002; 
Basile, 2003; Fonarow et al., 2008; Schimmer et al., 2009). Therefore, if in the later phases of beta-blocker treatment patients experienced worsening of the lung function it will not necessarily lead to an immediate modulation of the betablocker dosage which in turn potentially might happen at the next healthcare contact (Fonarow et al., 2008). Consequently, a sub-clinical effect of beta-blockade on the respiratory system summed with an ongoing exacerbation of the respiratory disease may results in a synergic negative effect in terms of respiratory symptomatology, which could result intolerable for patients and culminate in a hospitalization or beta-blocker discontinuation. A plausible explanation for why we observed an increased risk of heart failure hospitalization could be related to the prolonged $\beta 2$-adrenoreceptor antagonism performed by beta-blockers less selective for $\beta 1$-adrenoreceptor receptors. In particular carvedilol, as recently proved in clinical settings, can alter pulmonary compliance leading to dynamic hyperinflation even in presence of $\beta 2$-adrenoreceptor agonists and corticosteroids (Jabbal and Lipworth, 2018). Dynamic hyperinflation, in turn, apart from negative respiratory outcomes, can promote impaired ventricular filling and low cardiac output along with a reduction of intrathoracic blood volume and pulmonary vein dimensions, all phenomenon that can promote decompensation of heart failure (O'Donnell et al., 2015) From clinical and public health perspectives, whenever confirmed with further evidence, this study opens new possibilities for improving the prognosis of beta-blocker treated patients with concurrent COPD or asthma, and to minimize the burden associated with their clinical management. We estimated that just by switching from carvedilol to metoprolol/bisoprolol/nebivolol it was theoretically possible to reduce 106 cases (95\%CI 76-134) of heart failure hospitalization and 131 cases (95\%CI 62-201) of beta-blocker discontinuation per 10,000 person-years of observational period. There is unfortunately only a speculative explanation of the results. The observation would benefit for additional data to investigate why increase hospitalization for heart failure, but not COPD is caused by the use of non-selective beta-blockers.

\section{Strengths and Limitations}

Despite promising, our results should be considered in virtue of a set of limitations. The first is related to data sources. Caserta Local Health Unit administrative databases include information on drugs redemption and hospitalization occurred in in the catchment area of Caserta. Despite poorly likelihood, if a patient redeemed a prescription or if the person was hospitalized outside this area, the information is potentially lost. The second limitation is the limited access to historical data. We had less than a decade of observation period for our cohorts that do not permit the determination of the first hospitalization for a certain diagnosis (such as heart failure, asthma and COPD). In fact, we did not have the chance to assess for patients, the first date of betablocker administration and the date of their first hospitalization for heart failure or COPD. The third limitation is the lacking of indication of use for redeemed drugs that do not exclude the misclassification of some patients in our study population. In an example, it could not be ruled out that the indication of use of R03 drugs was for asthma instead of COPD. On the other hand, the major strengths of this study are the sample size, the long followup period, and inclusion of the entire population of Caserta minimizing the risk of selection biases. Moreover, the possibility of relying on real-world data from routine clinical practice which provide "evidence" that may directly support changes in clinical practice and policy decisions, especially in Caserta Local Health Unit (Romio et al., 2013).

\section{CONCLUSION}

In the present study, patients with heart failure and concurrent respiratory disease were followed for 5 years. Carvedilol, a non-selective beta-adrenoreceptor blocker, was associated with an increased risk of discontinuation if compared to metoprolol, bisoprolol or nebivolol. Moreover, it was associated with an increased risk of heart failure hospitalization. We estimated that just by switching from carvedilol to metoprolol/bisoprolol/nebivolol it was theoretically possible to reduce heart failure hospitalization and beta-blocker discontinuation.

\section{DATA AVAILABILITY}

The raw data supporting the conclusions of this manuscript will be made available from the authors on request, with legal reservations.

\section{AUTHOR CONTRIBUTIONS}

MS and AM developed the concept and designed the study. MS, $\mathrm{AM}, \mathrm{AC}$, and LS analyzed or interpreted the data. MS, AM, DR, MJ, AC, FR, and LS wrote the paper. All authors drafted the paper and revised it for important intellectual content and approved the final version of the manuscript to be published.

\section{FUNDING}

MS postdoc was supported by a grant from the Novo Nordisk Foundation to the University of Copenhagen (NNF15SA0018404). This study resulted from the strict partnership between University of Campania "L. Vanvitelli", Campania Pharmacovigilance Regional Centre, and Caserta Local Health Unit. In particular, it is part of a set of studies that aimed to promote drug safety in Campania Region (Cammarota et al., 2014; Casula et al., 2014; Parretta et al., 2014; Illario et al., 2015; Sessa et al., 2015, 2016a,b,c,d, 2017a,b,c; Mascolo et al., 2016, 2017a,b; Rafaniello et al., 2016; Scavone et al., 2016, 2017).

\section{SUPPLEMENTARY MATERIAL}

The Supplementary Material for this article can be found online at: https://www.frontiersin.org/articles/10.3389/fphar. 2018.01212/full\#supplementary-material 


\section{REFERENCES}

Agenzia Italiana del Farmaco (2008). Linee Guida per la Classificazione e la Conduzione Degli Studi Osservazionali Sui Farmaci. Available at: https://www.agenziafarmaco.gov.it/ricclin/sites/default/files/files_wysiwyg/ files/Normativa/DETERMINAZ_AIFA_20_Marzo_2008_ST_OSS.pdf [accessed December 19, 2017].

Andersson, C., Vaag, A., Selmer, C., Schmiegelow, M., Sorensen, R., Lindhardsen, J., et al. (2012). Risk of cancer in patients using glucose-lowering agents: a nationwide cohort study of 3.6 million people. BMJ Open 2:e000433. doi: 10. 1136/bmjopen-2011-000433

Austin, P. C. (2014). A comparison of 12 algorithms for matching on the propensity score. Stat. Med. 33, 1057-1069. doi: 10.1002/sim.6004

Baker, J. G., and Wilcox, R. G. (2017). beta-blockers, heart disease and COPD: current controversies and uncertainties. Thorax 72, 271-276. doi: 10.1136/ thoraxjnl-2016-208412

Barr, R. G., Ahmed, F. S., Carr, J. J., Hoffman, E. A., Jiang, R., Kawut, S. M., et al. (2012). Subclinical atherosclerosis, airflow obstruction and emphysema: the MESA lung study. Eur. Respir. J. 39, 846-854. doi: 10.1183/09031936.00165410

Basile, J. N. (2003). Titration of beta-blockers in heart failure. How to maximize benefit while minimizing adverse events. Postgrad. Med. 113, 63-70; quiz 3. doi: 10.3810/pgm.2003.03.1389

Bousquet, J., Clark, T. J. H., Hurd, S., Khaltaev, N., Lenfant, C., O'byrne, P., et al. (2007). GINA guidelines on asthma and beyond. Allergy 62, 102-112. doi: 10.1111/j.1398-9995.2006.01305.x

Cammarota, S., Bruzzese, D., Catapano, A. L., Citarella, A., De Luca, L., Manzoli, L., et al. (2014). Lower incidence of macrovascular complications in patients on insulin glargine versus those on basal human insulins: a population-based cohort study in Italy. Nutr. Metab. Cardiovasc. Dis. 24, 10-17. doi: 10.1016/j. numecd.2013.04.002

Casula, M., Catapano, A. L., Piccinelli, R., Menditto, E., Manzoli, L., De Fendi, L., et al. (2014). Assessment and potential determinants of compliance and persistence to antiosteoporosis therapy in Italy. Am. J. Manag. Care 20, e138e145.

Chong, L. K., Suvarna, K., Chess-Williams, R., and Peachell, P. T. (2003). Desensitization of beta2-adrenoceptor-mediated responses by short-acting beta2-adrenoceptor agonists in human lung mast cells. Br. J. Pharmacol. 138, 512-520. doi: 10.1038/sj.bjp.0705050

Davis, C. H., MacKinnon, D. P., Schultz, A., and Sandler, I. (2003). Cumulative risk and population attributable fraction in prevention. J. Clin. Child Adolesc. Psychol. 32, 228-235. doi: 10.1207/S15374424JCCP3202-7

Dickstein, K., Cohen-Solal, A., Filippatos, G., McMurray, J. J. V., Ponikowski, P., Poole-Wilson, P. A., et al. (2008). ESC guidelines for the diagnosis and treatment of acute and chronic heart failure 2008: the task force for the diagnosis and treatment of acute and chronic heart failure 2008 of the European society of cardiology. Developed in collaboration with the heart. Eur. Heart J. 29, 2388-2442. doi: 10.1093/eurheartj/ehn309

Dickstein, K., Vardas, P. E., Auricchio, A., Daubert, J.-C., Linde, C., McMurray, J., et al. (2010). 2010 Focused Update of ESC Guidelines on device therapy in heart failure: an update of the 2008 ESC Guidelines for the diagnosis and treatment of acute and chronic heart failure and the 2007 ESC Guidelines for cardiac and resynchronization therapy. Developed with the special contribution of the heart failure association and the European Heart rhythm association. Eur. Soc. Cardiol. 12, 1526-1536. doi: 10.1093/europace/euq392

Du, Q., Sun, Y., Ding, N., Lu, L., and Chen, Y. (2014). Beta-blockers reduced the risk of mortality and exacerbation in patients with COPD: a meta-analysis of observational studies. PLoS One 9:e113048. doi: 10.1371/journal.pone.0113048

Dungen, H.-D., Apostolovic, S., Inkrot, S., Tahirovic, E., Topper, A., Mehrhof, F., et al. (2011). Titration to target dose of bisoprolol vs. carvedilol in elderly patients with heart failure: the CIBIS-ELD trial. Eur. J. Heart Fail. 13, 670-680. doi: 10.1093/eurjhf/hfr020

Etminan, M., Jafari, S., Carleton, B., and FitzGerald, J. M. (2012). Beta-blocker use and COPD mortality: a systematic review and meta-analysis. BMC Pulm. Med. 12:48. doi: 10.1186/1471-2466-12-48

Fonarow, G. C., Abraham, W. T., Albert, N. M., Stough, W. G., Gheorghiade, M., Greenberg, B. H., et al. (2008). Dosing of beta-blocker therapy before, during, and after hospitalization for heart failure (from organized program to initiate lifesaving treatment in hospitalized patients with heart failure). Am. J. Cardiol. 102, 1524-1529. doi: 10.1016/j.amjcard.2008.07.045

Gottlieb, S. S., Fisher, M. L., Kjekshus, J., Deedwania, P., Gullestad, L., Vitovec, J., et al. (2002). Tolerability of beta-blocker initiation and titration in the metoprolol CR/XL randomized intervention trial in congestive heart failure (MERIT-HF). Circulation 105, 1182-1188. doi: 10.1161/hc1002.105180

Grieco, M. H., and Pierson, R. N. Jr. (2017). Mechanism of bronchoconstriction due to beta adrenergic blockade. J. Allergy Clin. Immunol. 48, 143-152. doi: 10.1016/0091-6749(71)90009-1

Hausdorff, W. P., Caron, M. G., and Lefkowitz, R. J. (1990). Turning off the signal: desensitization of beta-adrenergic receptor function. FASEB J. Off. Publ. Fed. Am. Soc. Exp. Biol. 4, 2881-2889. doi: 10.1096/fasebj.4.11.2165947

Hawkins, N. M., MacDonald, M. R., Petrie, M. C., Chalmers, G. W., Carter, R., Dunn, F. G., et al. (2009). Bisoprolol in patients with heart failure and moderate to severe chronic obstructive pulmonary disease: a randomized controlled trial. Eur. J. Heart Fail. 11, 684-690. doi: 10.1093/eurjhf/hfp066

Illario, M., Vollenbroek-Hutten, M., Molloy, D. W., Menditto, E., Iaccarino, G., and Eklund, P. (2015). Active and healthy ageing and independent living. J. Aging Res. 2015:542183. doi: 10.1155/2015/542183

Italian Medicine Agency (2017). Italian Medicine Agency - Reimbursed Drugs. Ital. Med. Agency Website. Available at: http://www.aifa.gov.it/content/tabellefarmaci-di-classe-e-h-al-15092017

Jabbal, S., and Lipworth, B. J. (2018). Sensitivity of lung resistance and compliance to beta-blocker induced bronchoconstriction and long acting beta-agonist withdrawal in COPD. Lung 196, 15-18. doi: 10.1007/s00408-017-0079-1

Jabbour, A., Macdonald, P. S., Keogh, A. M., Kotlyar, E., Mellemkjaer, S., Coleman, C. F., et al. (2010). Differences between beta-blockers in patients with chronic heart failure and chronic obstructive pulmonary disease: a randomized crossover trial. J. Am. Coll. Cardiol. 55, 1780-1787. doi: 10.1016/j.jacc.2010.01. 024

Jorgensen, K., Muller, M. F., Nel, J., Upton, R. N., Houltz, E., and Ricksten, S.E. (2007). Reduced intrathoracic blood volume and left and right ventricular dimensions in patients with severe emphysema: an MRI study. Chest 131, 1050-1057. doi: 10.1378/chest.06-2245

Kubota, Y., Asai, K., Furuse, E., Nakamura, S., Murai, K., Tsukada, Y. T., et al. (2015). Impact of beta-blocker selectivity on long-term outcomes in congestive heart failure patients with chronic obstructive pulmonary disease. Int. J. Chron. Obstruct. Pulmon. Dis. 10, 515-523. doi: 10.2147/COPD.S79942

Lainscak, M., Podbregar, M., Kovacic, D., Rozman, J., and von Haehling, S. (2011). Differences between bisoprolol and carvedilol in patients with chronic heart failure and chronic obstructive pulmonary disease: a randomized trial. Respir. Med. 105(Suppl.), S44-S49. doi: 10.1016/S0954-6111(11)70010-5

Lim, K. P., Loughrey, S., Musk, M., Lavender, M., and Wrobel, J. P. (2017). Betablocker under-use in COPD patients. Int. J. Chron. Obstruct. Pulmon. Dis. 12, 3041-3046. doi: 10.2147/COPD.S144333

Lohse, M. J., Engelhardt, S., Danner, S., and Bohm, M. (1996). Mechanisms of betaadrenergic receptor desensitization: from molecular biology to heart failure. Basic Res. Cardiol. 91(Suppl. 2), 29-34. doi: 10.1007/BF00795359

Loth, D. W., Brusselle, G. G., Lahousse, L., Hofman, A., Leufkens, H. G. M., and Stricker, B. H. (2014). beta-adrenoceptor blockers and pulmonary function in the general population: the rotterdam study. Br. J. Clin. Pharmacol. 77, 190-200. doi: 10.1111/bcp.12181

Mascolo, A., Rafaniello, C., Sportiello, L., Sessa, M., Cimmaruta, D., Rossi, F., et al. (2016). Dipeptidyl peptidase (DPP)-4 inhibitor-induced Arthritis/Arthralgia: a review of clinical cases. Drug Saf. 39, 401-407. doi: 10.1007/s40264-016-0399-8

Mascolo, A., Scavone, C., Sessa, M., di Mauro, G., Cimmaruta, D., Orlando, V., et al. (2017a). Can causality assessment fulfill the new European definition of adverse drug reaction? A review of methods used in spontaneous reporting. Pharmacol. Res. 123, 122-129. doi: 10.1016/j.phrs.2017.07.005

Mascolo, A., Sessa, M., Scavone, C., De Angelis, A., Vitale, C., Berrino, L., et al. (2017b). New and old roles of the peripheral and brain renin-angiotensinaldosterone system (RAAS): focus on cardiovascular and neurological diseases. Int. J. Cardiol. 227, 734-742. doi: 10.1016/j.ijcard.2016.10.069

McMurray, J. J. V., Adamopoulos, S., Anker, S. D., Auricchio, A., Bohm, M., Dickstein, K., et al. (2012). ESC guidelines for the diagnosis and treatment 
of acute and chronic heart failure 2012: the task force for the diagnosis and treatment of acute and chronic heart failure 2012 of the European society of cardiology. Developed in collaboration with the heart. Eur. J. Heart Fail. 14, 803-869. doi: 10.1093/eurjhf/hfs105

Morales, D. R., Jackson, C., Lipworth, B. J., Donnan, P. T., and Guthrie, B. (2014). Adverse respiratory effect of acute beta-blocker exposure in asthma: a systematic review and meta-analysis of randomized controlled trials. Chest 145 , 779-786. doi: 10.1378/chest.13-1235

Morales, D. R., Lipworth, B. J., Donnan, P. T., Jackson, C., and Guthrie, B. (2017). Respiratory effect of beta-blockers in people with asthma and cardiovascular disease: population-based nested case control study. BMC Med. 15:18. doi: 10.1186/s12916-017-0781-0

O'Donnell, D. E., Webb, K. A., and Neder, J. A. (2015). Lung hyperinflation in COPD: applying physiology to clinical practice. COPD Res. Pract. 1:4. doi: 10.1186/s40749-015-0008-8

Parretta, E., Rafaniello, C., Magro, L., Coggiola Pittoni, A., Sportiello, L., Ferrajolo, C., et al. (2014). Improvement of patient adverse drug reaction reporting through a community pharmacist-based intervention in the Campania region of Italy. Expert Opin. Drug Saf. 13(Suppl. 1), S21-S29. doi: 10.1517/14740338.2014.939582

Ponikowski, P., Voors, A. A., Anker, S. D., Bueno, H., Cleland, J. G. F., Coats, A. J. S., et al. (2016). 2016 ESC Guidelines for the diagnosis and treatment of acute and chronic heart failure: the task force for the diagnosis and treatment of acute and chronic heart failure of the European society of cardiology (ESC). Developed with the special contribution. Eur. J. Heart Fail. 18, 891-975. doi: 10.1002/ejhf.592

Rafaniello, C., Ferrajolo, C., Sullo, M. G., Sessa, M., Sportiello, L., Balzano, A., et al. (2016). Risk of gastrointestinal complications associated to NSAIDs, lowdose aspirin and their combinations: results of a pharmacovigilance reporting system. Pharmacol. Res. 104, 108-114. doi: 10.1016/j.phrs.2015.12.026

Romio, S., Sturkenboom, M., and Corrao, G. (2013). Real-world data from the health decision maker perspective. What are we talking about?. Epidemiol. Biostat. Public Health 10, e89791-e89799. doi: 10.2427/8979

Rutten, F. H., Zuithoff, N. P. A., Hak, E., Grobbee, D. E., and Hoes, A. W. (2010). Beta-blockers may reduce mortality and risk of exacerbations in patients with chronic obstructive pulmonary disease. Arch. Intern. Med. 170, 880-887. doi: 10.1001/archinternmed.2010.112

Salpeter, S. R., Ormiston, T. M., and Salpeter, E. E. (2002). Cardioselective betablockers in patients with reactive airway disease: a meta-analysis. Ann. Intern. Med. 137, 715-725. doi: 10.7326/0003-4819-137-9-200211050-00035

Scavone, C., Sportiello, L., Rafaniello, C., Mascolo, A., Sessa, M., Rossi, F., et al. (2016). New era in treatment options of chronic hepatitis C: focus on safety of new direct-acting antivirals (DAAs). Expert Opin. Drug Saf. 15(Suppl. 2), 85-100. doi: 10.1080/14740338.2016.1221396

Scavone, C., Sportiello, L., Sullo, M. G., Ferrajolo, C., Ruggiero, R., Sessa, M., et al. (2017). Safety profile of anticancer and immune-modulating biotech drugs used in a real world setting in Campania region (Italy): bio-cam observational study. Front. Pharmacol. 8:607. doi: 10.3389/fphar.2017.00607

Schimmer, J. J., Billups, S. J., and Delate, T. (2009). Beta-blocker therapy in patients with left ventricular systolic dysfunction and chronic obstructive lung disease in an ambulatory care setting. Pharm. Pract. 7, 205-212. doi: 10.4321/S188636552009000400003

Sessa, M., Mascolo, A., Andersen, M. P., Rosano, G., Rossi, F., Capuano, A., et al. (2016a). Effect of chronic kidney diseases on mortality among digoxin users treated for non-valvular atrial fibrillation: a nationwide register-based retrospective cohort study. PLoS One 11:e0160337. doi: 10.1371/journal.pone. 0160337

Sessa, M., Mascolo, A., Mortensen, R. N., Andersen, M. P., Rosano, G. M. C., Capuano, A., et al. (2017a). Relationship between heart failure, concurrent chronic obstructive pulmonary disease and beta-blocker use: a Danish nationwide cohort study. Eur. J. Heart Fail. 20, 548-556. doi: 10.1002/ejhf.1045

Sessa, M., Rafaniello, C., Sessa, M., Bernardi, F. F., Pozzi, M., Cheli, S., et al. (2017b). The predictive value of ABCB1, ABCG2, CYP3A4/5 and CYP2D6 polymorphisms for risperidone and aripiprazole plasma concentrations and the occurrence of adverse drug reactions. Pharm. J. 18, 422-430. doi: 10.1038/tpj. 2017.38

Sessa, M., Rafaniello, C., Sportiello, L., Mascolo, A., Scavone, C., Maccariello, A., et al. (2016b). Campania region (Italy) spontaneous reporting system and preventability assessment through a case-by-case approach: a pilot study on psychotropic drugs. Expert Opin. Drug Saf. 15, 9-15. doi: 10.1080/14740338. 2016.1221397

Sessa, M., Rossi, C., Mascolo, A., Grassi, E., Fiorentino, S., Scavone, C., et al. (2015). Suspected adverse reactions to contrast media in Campania region (Italy): results from 14 years of post-marketing surveillance. Expert Opin. Drug Saf. 14, 1341-1351. doi: 10.1517/14740338.2015.1067301

Sessa, M., Rossi, C., Mascolo, A., Scavone, C., di Mauro, G., Grassi, R., et al. (2017c). Contrast media-induced nephropathy: how has Italy contributed in the past 30 years? A systematic review. Ther. Clin. Risk Manag. 13, 1463-1478. doi: $10.2147 /$ TCRM.S144418

Sessa, M., Rossi, C., Rafaniello, C., Mascolo, A., Cimmaruta, D., Scavone, C., et al. (2016c). Campania preventability assessment committee: a focus on the preventability of the contrast media adverse drug reactions. Expert Opin. Drug Saf. 15, 51-59. doi: 10.1080/14740338.2016.1226280

Sessa, M., Sullo, M. G., Mascolo, A., Cimmaruta, D., Romano, F., Puca, R. V., et al. (2016d). A case of figurate urticaria by etanercept. J. Pharmacol. Pharmacother. 7, 106-108. doi: 10.4103/0976-500X.184777

Short, P. M., Anderson, W. J., Williamson, P. A., and Lipworth, B. J. (2014). Effects of intravenous and oral beta-blockade in persistent asthmatics controlled on inhaled corticosteroids. Heart 100, 219-223. doi: 10.1136/heartjnl-2013-304769

Short, P. M., Lipworth, S. I. W., Elder, D. H. J., Schembri, S., and Lipworth, B. J. (2011). Effect of beta blockers in treatment of chronic obstructive pulmonary disease: a retrospective cohort study. BMJ 342:d2549. doi: 10.1136/bmj.d2549

Stone, I. S., Barnes, N. C., James, W.-Y., Midwinter, D., Boubertakh, R., Follows, R., et al. (2016). Lung deflation and cardiovascular structure and function in chronic obstructive pulmonary disease. A randomized controlled trial. Am. J. Respir. Crit. Care Med. 193, 717-726. doi: 10.1164/rccm.201508$1647 \mathrm{OC}$

van der Woude, H. J., Zaagsma, J., Postma, D. S., Winter, T. H., van Hulst, M., and Aalbers, R. (2005). Detrimental effects of beta-blockers in COPD: a concern for nonselective beta-blockers. Chest 127, 818-824. doi: 10.1378/chest.127. 3.818

Vaughan Williams, E. M. (1984). A classification of antiarrhythmic actions reassessed after a decade of new drugs. J. Clin. Pharmacol. 24, 129-147. doi: 10.1002/j.1552-4604.1984.tb01822.x

Watz, H. (2016). Chronic obstructive pulmonary disease: when pulmonologists do something good for the heart. Am. J. Respir. Crit. Care Med. 193, 703-704. doi: 10.1164/rccm.201512-2340ED

Watz, H., Waschki, B., Meyer, T., Kretschmar, G., Kirsten, A., Claussen, M., et al. (2010). Decreasing cardiac chamber sizes and associated heart dysfunction in COPD: role of hyperinflation. Chest 138, 32-38. doi: 10.1378/chest.09-2810

Xu, Y., Cheung, Y. B., Lam, K. F., Tan, S. H., and Milligan, P. (2010). A simple approach to the estimation of incidence rate difference. Am. J. Epidemiol. 172, 334-343. doi: 10.1093/aje/kwq099

Conflict of Interest Statement: The authors declare that the research was conducted in the absence of any commercial or financial relationships that could be construed as a potential conflict of interest.

Copyright (c) 2018 Sessa, Mascolo, Scavone, Perone, Di Giorgio, Tari, Fucile, De Angelis, Rasmussen, Jensen, Kragholm, Rossi, Capuano and Sportiello. This is an open-access article distributed under the terms of the Creative Commons Attribution License (CC BY). The use, distribution or reproduction in other forums is permitted, provided the original author(s) and the copyright owner(s) are credited and that the original publication in this journal is cited, in accordance with accepted academic practice. No use, distribution or reproduction is permitted which does not comply with these terms. 